\title{
Association of SYNTAX score with myocardial injury in STEMI patients: a cardiac magnetic resonance study
}

\section{Guangren Gao}

Tianjin medical university

Lianrong Feng

Tianjin medical university

Jinguo Fu

Tianjin Medical University

Zhaoyang Huo

Tianjin Medical University

Lei Zhang

Tianjin Medical University

Ruishuang Zheng

Tianjin Medical University

Lei Wang

Tianjin Medical University

Jing Liu

Tianjin Medical University

Heping Niu

Tianjin Medical University

Fenghai Liu

Tianjin Medical University

\section{Liqing Kang}

Tianjin Medical University

Jieqiong Liu

Tianjin Medical University

Hui Liu

Tianjin Medical University

Xinru Zhang

Cangzhou People's Hospital

Jun Zhang ( $\nabla$ dr_zhangj@sina.com )

Department of Cardiology,Cangzhou Central Hospital, Cangzhou Teaching Hospital of Tianjin Medical University https://orcid.org/0000-0003-3787-875X 


\section{Research Article}

Keywords: Myocardial injury, SYNTAX score, Infarct size, Myocardial salvage index, ST-segment elevation myocardial infarction

Posted Date: March 22nd, 2021

DOl: https://doi.org/10.21203/rs.3.rs-295060/v1

License: (1) This work is licensed under a Creative Commons Attribution 4.0 International License.

Read Full License 


\section{Abstract}

SYNTAX score (SS) is positively correlated with postprocedural myocardial injury identified by high sensitivity cardiac troponin in patients undergone elective coronary artery intervention, evidences about the association of SS with myocardial injury in STEMI patients were still scarce. A total of 149 consecutive patients within $24 \mathrm{~h}$ of STEMI were enrolled in the study. Both angiography and cardiac magnetic resonance (CMR) were performed during hospitalization. The time was $7.05 \mathrm{~h}(4.44,95.91, \mathrm{IQR})$ from symptom to angiography and $7.31 \pm 2.60$ days from symptom to CMR. The total median SS was $17(9-25, I Q R)$. In terms of myocardial injury parameters, there was a positive correlation between SS and infarct size (IS) ( $p<0.001$, Spearman $r=0.292)$, and negative correlation between SS and myocardial salvage index (MSI) $(p<0.001$, Spearman $r=-0.314)$. There was no significant correlation between SS and area at risk, microvascular obstruction or intramyocardial hemorrhage. According to SS, patients were divided into low SS (<22) (LSS) $(n=96)$ or mediate-high SS $(\geq 22)($ MHSS) $(n=53)$ group. In the multivariable model, after adjustment for important known predictors of IS, MHSS was significantly associated with high IS ( $\geq$ mean 35.43 ) (odd ratio $=2.245,95 \%$ confidence interval [1.002-5.053], $p=$ 0.048 ), as a continuous variate, SS was also significant associated with high IS (odd ratio $=1.053,95 \%$ confidence interval [1.014-1.095], $p=0.008)$. The areas under the receiver operating characteristic curves of SS for high IS and low MSI were 0.664 and 0.610 . Conclusion: of STEMI patients who presented to hospital within $24 \mathrm{~h}$ from symptom onset, SS was positively related with IS and negatively with MSI. SS was an independent predictor of IS after adjusting for important covariates.

\section{Introduction}

It was well established that in acute myocardial infarction patients, high infarct size (IS) and intramyocardial hemorrhage $(\mathrm{IMH})$ were closely related to bad prognosis[1, 2]. Microvascular obstruction (MVO) is the underlying cause for the no-reflow phenomenon in ST-segment elevation myocardial infarction (STEMI). The presence and extent of MVO measured by cardiovascular magnetic resonance imaging (CMR) after primary percutaneous coronary intervention (PCI) in STEMI are strongly associated with mortality and hospitalization for heart failure within 1 year and might be a better predictor of longterm major cardiovascular adverse events than IS[3,4].All these parameters, reflecting severity of myocardial injury, were typical indexes of CMR, which has emerged as a robust imaging modality for assessing patients after acute myocardial injury[5]. It is important to identify patients with severe myocardial injury so as to initiate intense care at early phase.

The anatomical Synergy between PCI with Taxus and Cardiac Surgery (SYNTAX) score is an important

instrument that can help clinicians to establish the optimum revascularization approach in patients with complex coronary artery disease (CAD)[6-9]. Previous studies found that SYNTAX score (SS) correlated significantly with cardiac troponin releases after elective $\mathrm{PCl}$ and could predicts peri-procedural myocardial injury defined as elevated troponin I at 6-24 h post-PCI[10, 11]. Therefore, it may be reasonable to assume that the complexity of CAD represented by SS is the surrogate of myocardial injury. 
The objective of this study was to investigate the association of SS with myocardial injury identified by CMR in STEMI patients.

\section{Method}

\section{Participants}

We conducted a single-center retrospective observational study at Cangzhou central hospital-a tertiary care hospital. We identified 276 STEMI patients undergone angiography between October 2018 and September 2020. The inclusion criteria were as follow: (1) electrocardiography (ECG) features consistent with acute STEMI (ST-segment elevation $\geq 1 \mathrm{~mm}$ in $\geq 2$ limb leads or $\geq 2 \mathrm{~mm}$ in $\geq 2$ contiguous precordial leads); (2) time duration within 24h from typical chest pain to hospitalization; (3) undergone CMR within $3 \sim 10$ days from symptom onset. A total of 127 patients were excluded for the following reasons: declined CMR for personal reasons $(n=16)$; old myocardial infarction history $(n=8)$; unstable clinical station( $n=39)$; claustrophobia( $n=3)$; undergone CMR over10 days from symptom onset $(n=10)$; hospitalization over $24 \mathrm{~h}$ from symptom onset $(n=51)$. Finally, 149 patients were enrolled for the analysis (Fig.1). The present study was approved by the ethical committee at Cangzhou Central Hospital. Requirement for informed consent was waived, because of the observational nature of the study.

\section{SYNTAX score}

The score calculator is available on the SS website (www.SYNTAXscore.com). Our analysis was performed by two independent operators. Every significant inter-observer difference required a recalculation.

\section{Laboratory tests, echocardiography and CMR[12,13]}

Blood samples were taken immediately after hospitalization, and ultrasound was performed $7 \pm 3$ days after PCI. CMR was performed using a 3.0-T scanner (GE Discovery MR750w; GE Healthcare, Milwaukee, WI, USA) with electrocardiographic-gated image acquisition. MRI parameters were measured on shortaxis images covering the entire left ventricle (8-/0-mm slice thickness/slice gap) with the following sequences: a steady-state free precession (SSFP) cine sequence to determine the left ventricular (LV) function, mass and volume and a short-tau inversion recovery T2-weighted (T2-STIR) sequence to determine the area at risk (AAR) of myocardial infarction. Late gadolinium enhancement (LGE) images were acquired approximately 10 15 min after the intravenous administration of gadolinium-based contrast medium $(0.2 \mathrm{mmol} / \mathrm{kg}$, Magnevist, gadopentetate dimeglumine injection, Bayer) to determine the IS.

Analysis was performed using dedicated software (cmr42 version 5.11.3, Circle Cardiovascular Imaging, Calgary, Alberta, Canada). Images were anonymized, batched, and analyzed in a blinded fashion by two experienced operators. The AAR was defined as high-signal myocardial edema mass/LV mass ratio. The IS was defined as the hyperenhanced myocardium on the LGE images and is expressed as the infarcted 
LV mass/LV mass ratio. MVO was defined as dark areas surrounded by hyperenhanced myocardium on the LGE images. The presence of intramyocardial hemorrhage $(\mathrm{IMH})$ was defined as hypointense areas within the brighter edematous zone on T2-STIR images. The papillary muscles were included in the LV cavity volume. The regions of interest (ROIs) for the volumes of $A A R$, IMH, IS, and MVO were created by manually drawing the lesion contours, while the LV volume was calculated by the semiautomated drawing of endocardial and epicardial contours for the whole LV myocardium on each slice. Myocardial edema was described as areas with a signal intensity $>5 \mathrm{SD}$ that of remote normal myocardium. The IS was calculated using the $>5$ SD method. Discordant cases were reviewed and reconciled with superior imaging specialists.

\section{Statistical methods}

SPSS was used for statistical analysis. Categorical data are presented as numbers and percentages, and continuous data are presented as the mean (standard deviation) or median (interquartile range).

Continuous variables with normal distributions were compared using the t-test. Continuous parameters that were not normally distributed were compared using the Mann-Whitney test. Categorical variables were compared using the chi-squared test (or Fisher's exact test when the expected value was <5). Independent predictors of high IS and low MSI were determined in a multivariate binary logistic regression model adjusted for all baseline variables found to be significant in the univariate analysis. Receiver operating characteristic (ROC) curves were generated to determine the usefulness of SS to discriminate high IS and low MSI. All statistical analyses were performed using SPSS version 20 (SPSS Inc, Chicago, IL, USA) and graphs produced using GraphPad Prism version 8.0 (GraphPad Software, La Jolla, CA, USA). A p value of $<0.05$ was regarded as statistically significant.

\section{Results}

\section{Patient characteristics}

Of a total 149 patients, mean age was $59.89 \pm 10.86$ years, $72.5 \%$ were male. The overall median SS was 17(IQR:9-25). According to SS, patients were divided into low SS (LSS) $(\mathrm{n}=96)$ or mediate-high SS (MHSS) $(n=53)$ group. Patient characteristics between two groups are shown in Table 1. Compared with LSS group, MHSS group had higher age and APOB, lower body weight index and creatinine clearance rate and a higher prevalence of multivessel disease, initial TIMI flow grade $0 / 1$, and initial TIMI thrombus grade $4 / 5$ (all $\mathrm{p}<0.05)$.

\section{TTE and CMR parameters}

All TTE parameters were comparable (Table 2). Whereas CMR showed a lower LVEF (45.65 $\pm 12.01 \mathrm{VS}$ 52.86 $\pm 13.45, \mathrm{p}=0.001), \mathrm{MSI}$ (24.52[IQR:13.92-35.69] VS 30.30[IQR:19.23-45.41], $\mathrm{p}=0.016)$ and higher LVESV (63.96[IQR:51.34-80.38], $p=0.029)$, IS (38.06 \pm 9.40 VS 33.93 $\pm 11.94, p=0.029)$ in MHSS group patients when compared with those in LSS group. There was no significant difference between two groups in terms of MVO, IMH and AAR (Table 2 and Fig.2). 


\section{Correlations between SS and CMR parameters}

Correlations between SS and CMR parameters are presented in Fig.3. SS had a positive correlation with IS $(\% L V)(r=0.292, p<0.001)$ and negative with MSI $(r=-0.314, p<0.001)$. An example is illustrated in Fig.4. The ROC of SS was $66.4 \%$ at IS(\%LV) $\geq$ mean 35.43 and $61.0 \%$ at MSI $\leq$ median 28.01(Fig.5).

\section{Univariate and multivariate logistic regression for IS $\geq$ mean 35.43 and myocardial salvage index $\leq$ median28.01}

After screening of all clinical ,procedural, laboratory and TTE parameters presented in both table 1 and table 2, the odd ratio (OR) for IS $\geq$ mean 35.43 was significant in 9 variables including initial heart rate, pro-BNP, CK, CKMB, LVEF-TTE, left ventricular end-diastolic diameter (LVEDD), infarct-related artery LAD, $S S \geq 22$ (as categorical variable) and SS (as continuous variable) (all $p<0.05$ ); the OR of LVEF-TTE, baseline TIMI flow 0/1 and SS (not as categorical variable) for lower MSI ( $\leq$ median28.01) were significant (Table 4). In multivariate logistic regression model for high IS, LVEF-TTE (OR, $\% 95 \mathrm{Cl}, 0.913(0.865,0.962), \mathrm{p}=0.001)$ and $\mathrm{SS} \geq 22(\mathrm{OR}, \% 95 \mathrm{Cl}, 2.245(1.002,5.053), \mathrm{p}=0.048)$ were significant in model 1(Fig.6); in model 2, LVEF-TTE (OR, \%95Cl,0.914(0.866,0.965), p=0.001) and SS (as continuous variable) $(\mathrm{OR}, \% 95 \mathrm{Cl}, 1.053(1.014,1.095), \mathrm{p}=0.008)$ were also the independent predictors of high IS; for low MSI, only LVEF-TTE $(\mathrm{OR}, \% 95 \mathrm{Cl}, 0.924(0.881,0.970), \mathrm{p}=0.001)$ was the independent predictor (Fig.6).

\section{Discussion}

The present study is, to the best of our knowledge, the first report on the relationship between SS and myocardial injury in STEMI patients presenting to hospital within $24 \mathrm{~h}$ from symptom onset. We identified three major findings:(1) there was a significant positive correlation between SS and IS and negative correlation between SS and MSI (Fig. 3). (2) compared with LSS group, MHSS group has lower LVEF deprived by CMR and higher LVESV, but LVEDV was comparable between groups. (3) according to the univariate and multivariate logistic models, SS (both as categorical variable and continuous variable) was the independent predictor of high IS after adjusted for confounders (Fig. 6).

In the CVLPRIT study[14], patients treated with a staged complete revascularization (CR) had higher SS

$(18.3,15-26$ vs. $16,12-21.5, p=0.021)$ than those treated with immediate CR. Interestingly, staged approach patients also had larger IS (\%LV) $(19.1,10.2-37.1$ vs. $11.6,6.8-17.6, p=0.006)$ and lower MSI $(35.1,5.9-66.4$ vs.61.7,37.4-75.5, $p=0.008)$ compared with immediate CR. However, there was no direct relationship among them were stated. In another several studies $[10,11,15,16]$, in patients undergone $\mathrm{CABG}$ or $\mathrm{PCl}, \mathrm{SS}$ was not only positively related to peri-procedural myocardial injury (deprived by elevated cardiac troponin and CKMB $6 \mathrm{~h}$ after operation), but also an independent predictor of it. The increase in release of cardiac biomarkers after selective $\mathrm{PCl}$ was significantly associated with the extent of atherosclerosis identified by the SS [17]. These findings were consistent with those of our study. Furthermore, in our study, there was no significant relationship between SS and AAR was detected, thus, 
the negative correlation between SS and MSI might be interpreted by the positive correlation between SS and IS.

In our study, the LVEF-TTE in LSS group was comparable with that in MHSS group ( $57.63 \pm 8.87$ VS

$54.77 \pm 9.55, p=0.070$ ), however, LVEF-CMR in LSS group was significantly higher than that in MHSS group ( $52.86 \pm 13.45$ VS $45.65 \pm 12.01, p=0.001)$. In our study population, LVEF-CMR was lower than LVEF-TTE, in parallel to another recent multicenter registry[18]. Compared with LVEF-TTE, LVEF-CMR significantly improved MACE prediction in the group of patients with echocardiography-LVEF $<50 \%$, and had better prognostic meaning[18].

The influence of SS on myocardial injury after STEMI could have important clinical implication. In China,

CMR was available in only few of large hospitals. Risk stratification for STEMI patients is very important. By evaluating the SS, we might find the patients who have high risk of myocardial injury. Despite numerous failures to date, the prevention and treatments for STEMI patients with high risk of myocardial injury should remain a focus of future cardiovascular research.

This study has a few limitations. First, the proportion of patients with specific SS group $(<22, n=96$;

$22 \leq \&<32, n=36 ;>32, n=17$ ) in our population was too small to allow conclusions in all 3 groups. Consequently, tests of interaction were underpowered, especially when adjusted for covariates. Therefore, bias from residual confounding factors could still be present. Second, although all patients were enrolled consecutively, part of them declined CMR for personal reasons or unstable clinical station, for example, severe heart failure; on the other hand, only patients presented to hospital within $24 \mathrm{~h}$ from symptom onset were included in our study population, thus it should be very cautious to interpretate the conclusions in the specific patients.

In conclusion, of STEMI patients within $24 \mathrm{~h}$ from symptom onset, SS was positively related with IS and negatively with MSI. SS was an independent predictor of IS after adjusting for important covariates.

\section{Declarations}

Funding None

Compliance with ethical standards

Conflict of interest The authors declare that they have no conflicts of interest.

\section{References}

1. Caulfield JB, Leinbach R, Gold H (1976) The relationship of myocardial infarct size and prognosis. Circulation 53(3 Suppl):I141-I144 
2. Husser O, Monmeneu JV, Sanchis J, Nunez J, Lopez-Lereu MP, Bonanad C, Chaustre F, Gomez C, Bosch MJ, Hinarejos R, Chorro FJ, Riegger GA, Llacer A, Bodi V (2013) Cardiovascular magnetic resonance-derived intramyocardial hemorrhage after STEMI: Influence on long-term prognosis, adverse left ventricular remodeling and relationship with microvascular obstruction. Int J Cardiol 167(5):2047-2054. doi:10.1016/j.ijcard.2012.05.055

3. van Kranenburg M, Magro M, Thiele H, de Waha S, Eitel I, Cochet A, Cottin Y, Atar D, Buser P, Wu E, Lee D, Bodi V, Klug G, Metzler B, Delewi R, Bernhardt P, Rottbauer W, Boersma E, Zijlstra F, van Geuns RJ (2014) Prognostic value of microvascular obstruction and infarct size, as measured by CMR in STEMI patients. JACC Cardiovasc Imaging 7(9):930-939

4. de Waha S, Patel MR, Granger CB, Ohman EM, Maehara A, Eitel I, Ben-Yehuda O, Jenkins P, Thiele H, Stone GW (2017) Relationship between microvascular obstruction and adverse events following primary percutaneous coro nary intervention for ST-segment elevation myocardial infarction: an individual patient data pooled analysis from seven randomized trials. Eur Heart J 38(47):3502-3510

5. Thygesen K, Alpert JS, Jaffe AS, Chaitman BR, Bax JJ, Morrow DA, White HD, Thygesen K, Alpert JS, Jaffe AS, Chaitman BR, Bax JJ, Morrow DA, White HD, Mickley H, Crea F, Van de Werf F, BucciarelliDucci C, Katus HA, Pinto FJ, Antman EM, Hamm CW, De Caterina R, Januzzi JL, Apple FS, Alonso Garcia MA, Underwood SR, Canty JM, Lyon AR, Devereaux PJ, Zamorano JL, Lindahl B, Weintraub WS, Newby LK, Virmani R, Vranckx P, Cutlip D, Gibbons RJ, Smith SC, Atar D, Luepker RV, Robertson RM, Bonow RO, Steg PG, O'Gara PT, Fox KAA, Hasdai D, Aboyans V, Achenbach S, Agewall S, Alexander T, Avezum A, Barbato E, Bassand J-P, Bates E, Bittl JA, Breithardt G, Bueno H, Bugiardini R, Cohen MG, Dangas G, de Lemos JA, Delgado V, Filippatos G, Fry E, Granger CB, Halvorsen S, Hlatky MA, Ibanez B, James S, Kastrati A, Leclercq C, Mahaffey KW, Mehta L, Müller C, Patrono C, Piepoli MF, Piñeiro D, Roffi M, Rubboli A, Sharma S, Simpson IA, Tendera M, Valgimigli M, van der Wal AC, Windecker S, Chettibi M, Hayrapetyan H, Roithinger FX, Aliyev F, Sujayeva V, Claeys MJ, Smajić E, Kala P, Iversen KK, El Hefny E, Marandi T, Porela P, Antov S, Gilard M, Blankenberg S, Davlouros P, Gudnason T, Alcalai R, Colivicchi F, Elezi S, Baitova G, Zakke I, Gustiene O, Beissel J, Dingli P, Grosu A, Damman P, Juliebø V, Legutko J, Morais J, Tatu-Chitoiu G, Yakovlev A, Zavatta M, Nedeljkovic M, Radsel P, Sionis A, Jemberg T, Müller C, Abid L, Abaci A, Parkhomenko A, Corbett S (2018) Fourth universal definition of myocardial infarction (2018). Eur Heart J. doi:10.1093/eurheartj/ehy462

6. Serruys PW, Morice MC, Kappetein AP, Colombo A, Holmes DR, Mack MJ, Ståhle E, Feldman TE, van den Brand M, Bass EJ, Van Dyck N, Leadley K, Dawkins KD, Mohr FW (2009) Percutaneous coronary intervention versus coronary-artery bypass grafting for severe coronary artery disease. New Engl J Med 360(10):961-972. doi:10.1056/NEJMoa0804626

7. Serruys PW, Onuma Y, Garg S, Sarno G, van den Brand M, Kappetein AP, Van Dyck N, Mack M, Holmes D, Feldman T, Morice MC, Colombo A, Bass E, Leadley K, Dawkins KD, van Es GA, Morel MA, Mohr FW (2009) Assessment of the SYNTAX score in the SYNTAX study. Eurolntervention 5(1):50-56. doi:10.4244/eijv5i1a9

8. Morice MC, Serruys PW, Kappetein AP, Feldman TE, Ståhle E, Colombo A, Mack MJ, Holmes DR, Torracca L, van Es GA, Leadley K, Dawkins KD, Mohr F (2010) Outcomes in patients with de novo left 
main disease treated with either percutaneous coronary intervention using paclitaxel-eluting stents or coronary artery bypass graft treatment in the Synergy Between Percutaneous Coronary Intervention with TAXUS and Cardiac Surgery (SYNTAX) trial. Circulation 121(24):2645-2653.

doi:10.1161/circulationaha.109.899211

9. Sianos G, Morel MA, Kappetein AP, Morice MC, Colombo A, Dawkins K, van den Brand M, Van Dyck N, Russell ME, Mohr FW, Serruys PW (2005) The SYNTAX Score: an angiographic tool grading the complexity of coronary artery disease. Eurolntervention 1(2):219-227

10. van Gaal WJ, Ponnuthurai FA, Selvanayagam J, Testa L, Porto I, Neubauer S, Banning AP (2009) The SYNTAX score predicts peri-procedural myocardial necrosis during percutaneous coronary intervention. Int J Cardiol 135(1):60-65. doi:10.1016/j.ijcard.2008.03.033

11. Abu Sharar H, Helfert S, Vafaie M, Pleger ST, Chorianopoulos E, Bekeredjian R, Katus HA, Giannitsis E (2020) Identification of patients at higher risk for myocardial injury following elective coronary artery intervention. Catheter Cardiovasc Interv 96(3):578-585. doi:10.1002/ccd.28549

12. Ekeloef S, Halladin N, Fonnes S, Jensen SE, Zaremba T, Rosenberg J, Jonsson G, Aarøe J, Gasbjerg LS, Rosenkilde MM, Gögenur I (2017) Effect of Intracoronary and Intravenous Melatonin on Myocardial Salvage Index in Patients with ST-Elevation Myocardial Infarction: a Randomized Placebo Controlled Trial. J Cardiovasc Transl Res 10(5-6):470-479. doi:10.1007/s12265-017-97687

13. Choudry F, Hamshere S, Saunders N, Veerapen J, Bavnbek K, Knight C, Pellerin D, Locca D, Westwood M, Rakhit R, Crake T, Kastrup J, Parmar M, Agrawal S, Jones D, Martin J, Mathur A (2016) A randomized double-blind control study of early intra-coronary autologous bone marrow cell infusion in acute myocardial infarction: the REGENERATE-AMI clinical trialt. Eur Heart J 37(3):256-263. doi:10.1093/eurheartj/ehv493

14. Khan JN, Nazir SA, Greenwood JP, Dalby M, Curzen N, Hetherington S, Kelly DJ, Blackman D, Ring A, Peebles C, Wong J, Sasikaran T, Flather M, Swanton H, Gershlick AH, McCann GP (2016) Infarct size following complete revascularization in patients presenting with STEMI: a comparison of immediate and staged in-hospital non-infarct related artery PCl subgroups in the CVLPRIT study. J Cardiovasc Magn Reson 18(1):85. doi:10.1186/s12968-016-0298-2

15. Namat RA, Burlacu A, Tinica G, Covic A, Mitu F (2020) Using the SYNTAX score to predict myocardial injury early after on-pump coronary artery bypass surgery: a single-centre experience analysis. Kardiochir Torakochirurgia Pol 17(2):76-82. doi:10.5114/kitp.2020.97263

16. Chen ZW, Yang HB, Chen YH, Ma JY, Qian JY, Ge JB (2017) Impact of multi-vessel therapy to the risk of periprocedural myocardial injury after elective coronary intervention: exploratory study. BMC Cardiovasc Disord 17(1):69. doi:10.1186/s12872-017-0501-x

17. de Azevedo DFC, Hueb W, Lima EG, Rezende PC, Linhares Filho JPP, de Carvalho GF, Martins EB, Nomura CH, Strunz CMC, Serrano Junior CV, Ramires JAF, Kalil Filho R (2020) Significant association of SYNTAX score on release of cardiac biomarkers in uncomplicated post-revascularization 
procedures among patients with stable multivessel disease: MASS-V Study group. Medicine 99(8):e18973. doi:10.1097/md.0000000000018973

18. Marcos-Garces V, Gavara J, Lopez-Lereu MP, Monmeneu JV, Rios-Navarro C, de Dios E, Perez N, Cànoves J, Gonzalez J, Minana G, Nunez J, de la Espriella R, Santas E, Moratal D, Chorro FJ, Valente F, Lorenzatti D, Rodríguez-Palomares JF, Ortiz-Pérez JT, Bodi V (2020) Ejection Fraction by Echocardiography for a Selective Use of Magnetic Resonance After Infarction. Circ Cardiovasc Imaging 13(12):e011491. doi:10.1161/circimaging.120.011491

\section{Tables}

Table 1 Demographic and Clinical characteristics of patients 
Whole $(\mathrm{n}=149)$

$\mathrm{SS}<22(\mathrm{n}=96)$

$S S \geq 22(n=53)$

$\mathrm{p}$

value

Baseline Characteristics

\begin{tabular}{|c|c|c|c|c|}
\hline Age & $59.89 \pm 10.86$ & $58.32 \pm 11.47$ & $62.72 \pm 9.09$ & 0.011 \\
\hline Male & $108(72.5)$ & $68(70.8)$ & $40(75.5)$ & 0.572 \\
\hline BMI & $25.78 \pm 3.42$ & $26.25 \pm 3.62$ & $24.92 \pm 2.86$ & 0.023 \\
\hline Hypertension & $64(43.0)$ & $45(46.9)$ & $19(35.8)$ & 0.228 \\
\hline Smoking & $91(61.1)$ & $56(58.3)$ & $35(66.0)$ & 0.385 \\
\hline Hyperlipidemia & $17(11.4)$ & $11(11.5)$ & $6(11.3)$ & 1.0 \\
\hline Diabetes & $35(23.5)$ & $21(21.9)$ & $14(26.4)$ & 0.550 \\
\hline Initial heart rate & $76.79 \pm 13.35$ & $76.53 \pm 11.69$ & $77.27 \pm 16.07$ & 0.645 \\
\hline GRACE score & $109.97 \pm 22.73$ & $107.32 \pm 22.81$ & $114.75 \pm 22.06$ & 0.089 \\
\hline CRUSADE score & $18.0(9.0,24.0)$ & $15.0(9.0,22.0)$ & $18.5(12.8,29.3)$ & 0.056 \\
\hline \multicolumn{5}{|c|}{ Procedural data for the patients } \\
\hline \multicolumn{5}{|l|}{ Pain to door } \\
\hline$\leq 6 \mathrm{~h}$ & $99(66.4)$ & $60(62.5)$ & $39(73.6)$ & 0.206 \\
\hline$>6 \mathrm{~h}$ & $50(33.6)$ & $36(37.5)$ & $14(26.4)$ & \\
\hline door to & $1.17(0.68,80.91)$ & $1.23(0.69,10.10)$ & $0.98(0.63,234.73)$ & 0.830 \\
\hline \multicolumn{5}{|c|}{ reperfusion/angiography } \\
\hline \multicolumn{5}{|l|}{ only(h) } \\
\hline Pain to reperfusion/ & $7.05(4.44,95.91)$ & $7.33(4.68,23.39)$ & $6.22(4.27,246.73)$ & 0.629 \\
\hline \multicolumn{5}{|l|}{ angiography only (h) } \\
\hline \multicolumn{5}{|l|}{ Culprit lesion } \\
\hline LAD & $60(40.3)$ & $37(38.5)$ & $23(43.4)$ & 0.603 \\
\hline Non-LAD & $89(59.7)$ & $59(61.5)$ & $30(56.6)$ & \\
\hline \multicolumn{5}{|c|}{ No. of diseased vessels } \\
\hline 0 & $4(2.7)$ & $4(4.2)$ & $0(0)$ & $<0.001$ \\
\hline 1 & $54(36.2)$ & $51(53.1)$ & $3(5.7)$ & \\
\hline 2 & $45(30.2)$ & $29(30.2)$ & $16(30.2)$ & \\
\hline 3 & $46(30.9)$ & $12(12.5)$ & $34(64.2)$ & \\
\hline \multicolumn{5}{|c|}{ Initial TIMI flow grade } \\
\hline $0 / 1$ & 93(62.4) & $52(54.2)$ & $41(77.4)$ & 0.008 \\
\hline $2 / 3$ & $56(37.6)$ & $44(45.8)$ & $12(22.6)$ & \\
\hline
\end{tabular}

Initial TIMI thombus grade 


\begin{tabular}{|c|c|c|c|}
\hline $0 \sim 3$ & $56(37.6)$ & $45(46.9)$ & $11(20.8)$ \\
\hline $4 / 5$ & $93(62.4)$ & $51(53.1)$ & $42(79.2)$ \\
\hline
\end{tabular}

Final TIMI flow grade

$\begin{array}{lllll}0 / 1 & 9(6.0) & 5(5.2) & 4(7.5) & 0.721 \\ 2 / 3 & 140(94.0) & 91(94.8) & 49(92.5) & \end{array}$

Post-dilatation in patients with stent implanting

$\begin{array}{lllll}\text { Yes } & 86(81.9) & 57(81.4) & 29(82.9) & 0.858 \\ \text { No } & 19(18.1) & 13(18.6) & 6(17.1) & \\ \text { de of reperfusion (n, \%) } & & & 12(22.6) & 0.675 \\ \text { Balloon angioplasty } & 29(19.5) & 17(17.7) & 35(66.0) & 6(11.3) \\ \text { PCI with stent } & 105(70.5) & 70(72.9) & 9(9.4) & \end{array}$

Laboratory data

Creatinine clearance rate 102.24(77.99,123.64)

111.12(79.81,127.97)

92.11(72.60,108.06) 0.016

cTnI

$0.32(0.03,4.08)$

$0.35(0.06,5.81)$

$0.18(0.03,2.27)$

0.207

WBC

$10.51 \pm 3.62$

$10.64 \pm 3.69$

$10.27 \pm 3.53$

0.566

AST

29.35(19.03,61.88)

$31.70(19.85,67.0)$

$26.80(18.60,55.20)$

0.378

CK

$176.0(108.5,579.0)$

218.0(110.75,616.0)

$158.0(96.0,558.25)$

0.337

CKMB

$25.55(16.13,75.90)$

25.85(16.33,61.68)

24.5(16.0,83.90)

0.821

LDL

$2.96 \pm 0.85$

$2.89 \pm 0.76$

$3.07 \pm 0.99$

0.272

APOA

$1.06 \pm 0.22$

$1.06 \pm 0.22$

$1.05 \pm 0.21$

0.704

APOB

$0.99 \pm 0.26$

$0.96 \pm 0.22$

$1.06 \pm 0.30$

0.038

Medication

Aspirin

146(98.0\%)

93(96.9)

53(100.0)

0.553

Clopidogrel

46(30.9)

33(34.4)

13(24.5)

0.358

Ticagrelor

101(67.8)

62(64.6)

39(73.6)

No clopidogrel or

2(1.3)

1(1.0)

1(1.9)

ticagrelor

Statin

143(96.0)

92(95.8)

51(96.2)

1.0

Beta blocker

86(57.7)

56(58.3)

30(56.6)

0.864

ACEI

6(4.0)

3(3.1)

3(5.7)

0.666

ARB

29(19.5)

17(17.7)

12(22.6)

0.519 
Categorical data is presented as absolute (percentage), normal distributed data as mean+ standard deviation, and other continuous data with medians including first and third quartiles in brackets

$B M I$ body weight index, GRACE the Global Registry of Acute Coronary Events, CRUSADE Can Rapid Risk Stratification of Unstable Angina Patients Suppress Adverse Outcomes With Early Implementation of the American College of Cardiology/American Heart Association Guidelines, LAD left anterior descending artery, TIMI thrombolysis in myocardial infarction, $W B C$ white blood cell, $L D L$ low density lipoprotein, ACEI AngiotensinConverting Enzyme Inhibitors, ARB Angiotensin Receptor Blocker,

Table 2 TTE and CMR imaging parameters 


\begin{tabular}{|c|c|c|c|c|}
\hline Characteristic & Whole & $\begin{array}{l}\text { SYNTAX score }<22 \\
(\mathrm{n}=96)\end{array}$ & $\begin{array}{l}\text { SYNTAX score } \\
\geq 22(n=53)\end{array}$ & $\begin{array}{l}\mathrm{p} \\
\text { value }\end{array}$ \\
\hline \multicolumn{5}{|l|}{ TTE } \\
\hline & $56.60 \pm 9.19$ & $57.63 \pm 8.87$ & $54.77 \pm 9.55$ & 0.070 \\
\hline \multicolumn{5}{|l|}{ LVEF, \% } \\
\hline LVEDD, mm & $49.32 \pm 6.30$ & $49.33 \pm 5.43$ & $49.29 \pm 7.67$ & 0.970 \\
\hline $\mathrm{LAD}, \mathrm{mm}$ & $37.75 \pm 4.96$ & $37.55 \pm 4.68$ & $38.12 \pm 5.48$ & 0.512 \\
\hline \multicolumn{5}{|l|}{ CMR } \\
\hline \multicolumn{4}{|l|}{ (days) } & 0.589 \\
\hline LVEF, \% & $50.29 \pm 13.37$ & $52.86 \pm 13.45$ & $45.65 \pm 12.01$ & 0.001 \\
\hline LVEDV, mL & $119.12(101.19,141.06)$ & $117.31(102.89,136.79)$ & $125.40(93.88,148.14)$ & 0.262 \\
\hline LVESV, mL & $55.01(43.99,75.05)$ & $51.28(38.23,72.17)$ & $63.96(51.34,80.38)$ & 0.004 \\
\hline IS, $\%$ of LV & $35.43 \pm 11.94$ & $33.97 \pm 12.95$ & $38.06 \pm 9.40$ & 0.029 \\
\hline \multicolumn{5}{|l|}{ MVO } \\
\hline No. (\%) & $54(36.2)$ & $35(36.5)$ & $19(35.8)$ & 1.0 \\
\hline$\%$ of LV & $1.35(0.40,3.20)$ & $1.0(0.4,3.1)$ & $1.4(0.4,4.7)$ & 0.690 \\
\hline$\%$ IS & $5.94(1.54,9.27)$ & $6.01(1.48,9.25)$ & $5.10(1.62,14.95)$ & 0.821 \\
\hline $\mathrm{ml}$ & $1.93(0.48,4.74)$ & $1.72(0.45,4.55)$ & $2.22(0.49,6.44)$ & 0.765 \\
\hline AAR (\% of LV) & $51.05 \pm 15.83$ & $50.83 \pm 16.18$ & $51.46 \pm 15.32$ & 0.821 \\
\hline \multicolumn{5}{|l|}{$\mathrm{IMH}$} \\
\hline No. (\%) & $32(21.5)$ & $22(22.9)$ & $10(18.9)$ & 0.678 \\
\hline $\mathrm{ml}$ & $1.46(0.56,5.01)$ & $1.75(0.68,4.88)$ & $1.08(0.42,6.35)$ & 0.535 \\
\hline$\%$ of (LV) & $0.87(0.48,2.97)$ & $1.13(0.47,2.93)$ & $0.59(0.40,4.24)$ & 0.675 \\
\hline$\% A A R$ & $3.25(1.10,8.18)$ & $3.70(1.62,7.31)$ & $2.21(0.79,12.39)$ & 0.589 \\
\hline MSI (\%) & $28.01(15.94,41.81)$ & $30.30(19.23,45.41)$ & $24.52(13.92,35.69)$ & 0.016 \\
\hline
\end{tabular}

Categorical data is presented as absolute (percentage), normal distributed data as mean+ standard deviation, and other continuous data with medians including first and third quartiles in brackets $T T E$ transthoracic echocardiography, $C M R$ cardiac magnetic resonance imaging, $L V E F$ left ventricular ejection fraction, $L V E D V$ left ventricular end-diastolic volume, LVESV left ventricular end-systolic volume, IS infarct size, $L V$ left ventricular, $M V O$ microvascular obstruction, $A A R$ area at risk, $I M H$ intramyocardial hemorrhage, $M S I$ myocardial salvage index 
Table 3 Correlations Among SYNTAX score and CMR parameters

\begin{tabular}{ccccccccc}
\hline $\begin{array}{c}\text { IMH } \\
(\% \mathrm{LV})\end{array}$ & $\begin{array}{c}\text { IMH } \\
(\% \mathrm{AAR})\end{array}$ & $\begin{array}{c}\text { MVO } \\
(\% \mathrm{IS})\end{array}$ & $\begin{array}{c}\text { MVO } \\
(\% \mathrm{LV})\end{array}$ & $\begin{array}{c}\text { MVO } \\
(\mathrm{ml})\end{array}$ & $\begin{array}{c}\text { IS } \\
(\% \mathrm{LV})\end{array}$ & $\begin{array}{c}\text { AAR } \\
(\% \mathrm{IS})\end{array}$ & MSI & \\
\cline { 1 - 6 } $\mathrm{r}($ Spearman) & 0.07 & 0.05 & 0.14 & 0.18 & 0.18 & 0.292 & 0.03 & -0.314 \\
$\mathrm{p}$ & 0.69 & 0.80 & 0.32 & 0.20 & 0.20 & $<0.001$ & 0.76 & $<0.001$ \\
$\mathrm{~N}$ & 32 & 32 & 54 & 54 & 54 & 149 & 149 & 149 \\
\hline
\end{tabular}

$C M R$ cardiac magnetic resonance imaging, IMH intramyocardial hemorrhage, $M V O$ microvascular obstruction, IS infarct size, $A A R$ area at risk, $M S I$ myocardial salvage index

Table 4 univariable logistic regression model for IS $\geq$ mean 35.43 and myocardial salvage index $\leq$ median28.01

\begin{tabular}{|c|c|c|c|}
\hline \multirow[t]{2}{*}{ Predictors } & \multicolumn{3}{|c|}{ Univariable model } \\
\hline & $\mathrm{p}$ value & Odds ratio & 95\% confidence index \\
\hline \multicolumn{4}{|l|}{ High IS ( $\geq$ mean 35.43) } \\
\hline Initial heart rate & 0.043 & 1.027 & $1.001-1.055$ \\
\hline Pro-BNP & 0.037 & 1.0 & $1.0-1.001$ \\
\hline CK & 0.010 & 1.001 & $1.0-1.001$ \\
\hline CKMB & 0.020 & 1.005 & $1.001-1.010$ \\
\hline LVEF-TTE & $<0.001$ & 0.892 & 0.847-0.939 \\
\hline LVEDD-TTE & 0.045 & 1.062 & $1.001-1.127$ \\
\hline IRA=LAD (ref. other arteries) & 0.020 & 2.214 & $1.131-4.334$ \\
\hline \multicolumn{4}{|l|}{ SYNTAX score } \\
\hline$\geq 22$ & 0.010 & 2.500 & $1.245-5.019$ \\
\hline as continuous variable & 0.001 & 1.059 & 1.024-1.095 \\
\hline \multicolumn{4}{|l|}{ Lower MSI ( $\leq$ median28.01) } \\
\hline LVEF-TTE & $<0.001$ & 0.918 & $0.875-0.962$ \\
\hline Baseline TIMI flow 0/1 (ref. TIMI flow 2/3) & 0.036 & 2.119 & $1.049-4.280$ \\
\hline \multicolumn{4}{|l|}{ SYNTAX score } \\
\hline Continuous variable & 0.020 & 1.039 & $1.006-1.073$ \\
\hline$\geq 22$ & 0.214 & 1.561 & $0.773-3.152$ \\
\hline
\end{tabular}

IS infarct size, LVEF left ventricular ejection fraction, TTE transthoracic echocardiography, $L V E D D$ left ventricular end-diastolic diameter, IRA infarct related artery, LAD left anterior descending artery, MSI myocardial salvage index, TIMI thrombolysis in myocardial infarction

\section{Figures}


276 AMI cases undewent angiography from October 2018 to September 2020

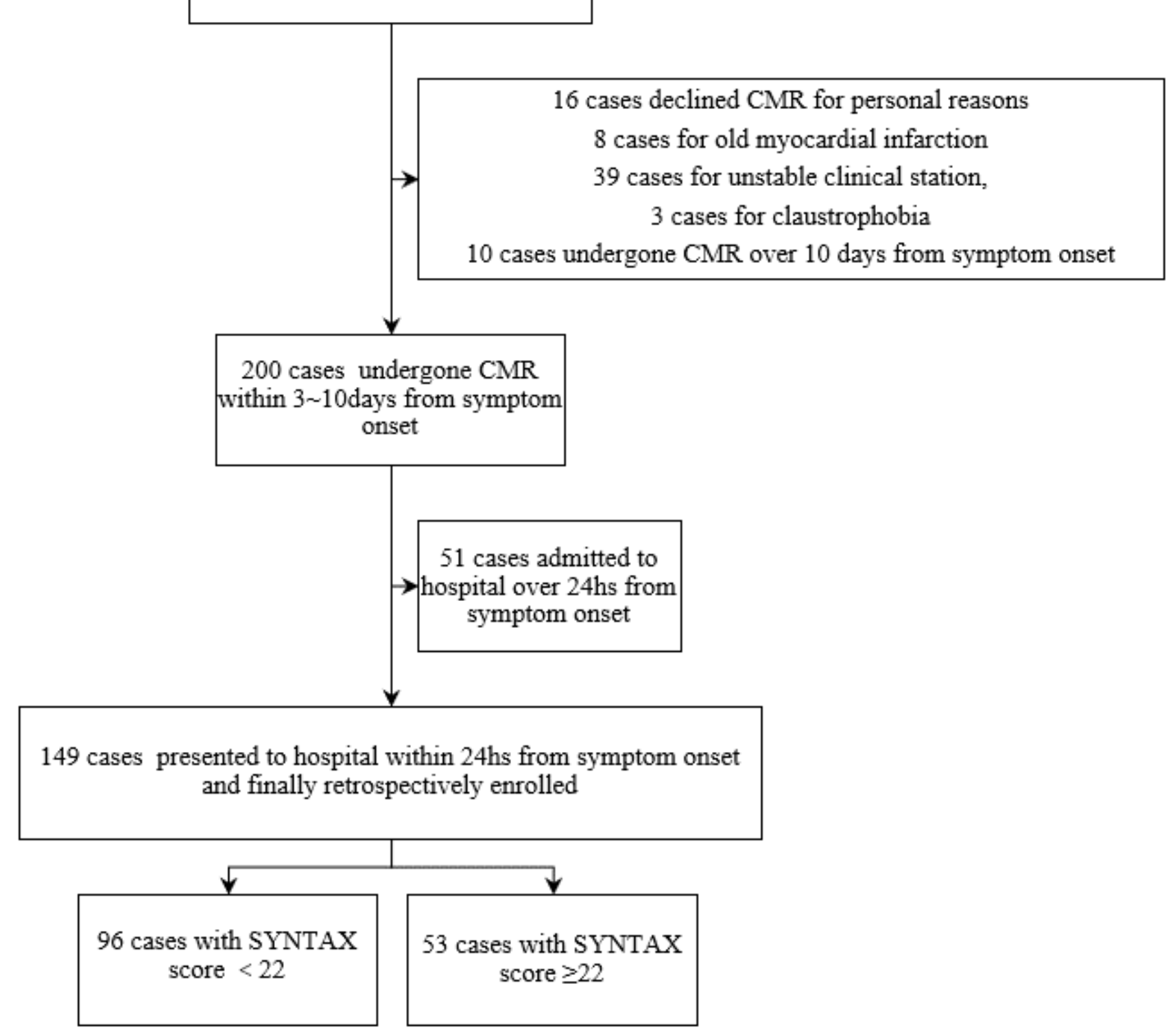

\section{Figure 1}

Study flow chart of patient enrollment AMI acute myocardial infarction, CMR cardiac magnetic resonance imaging 


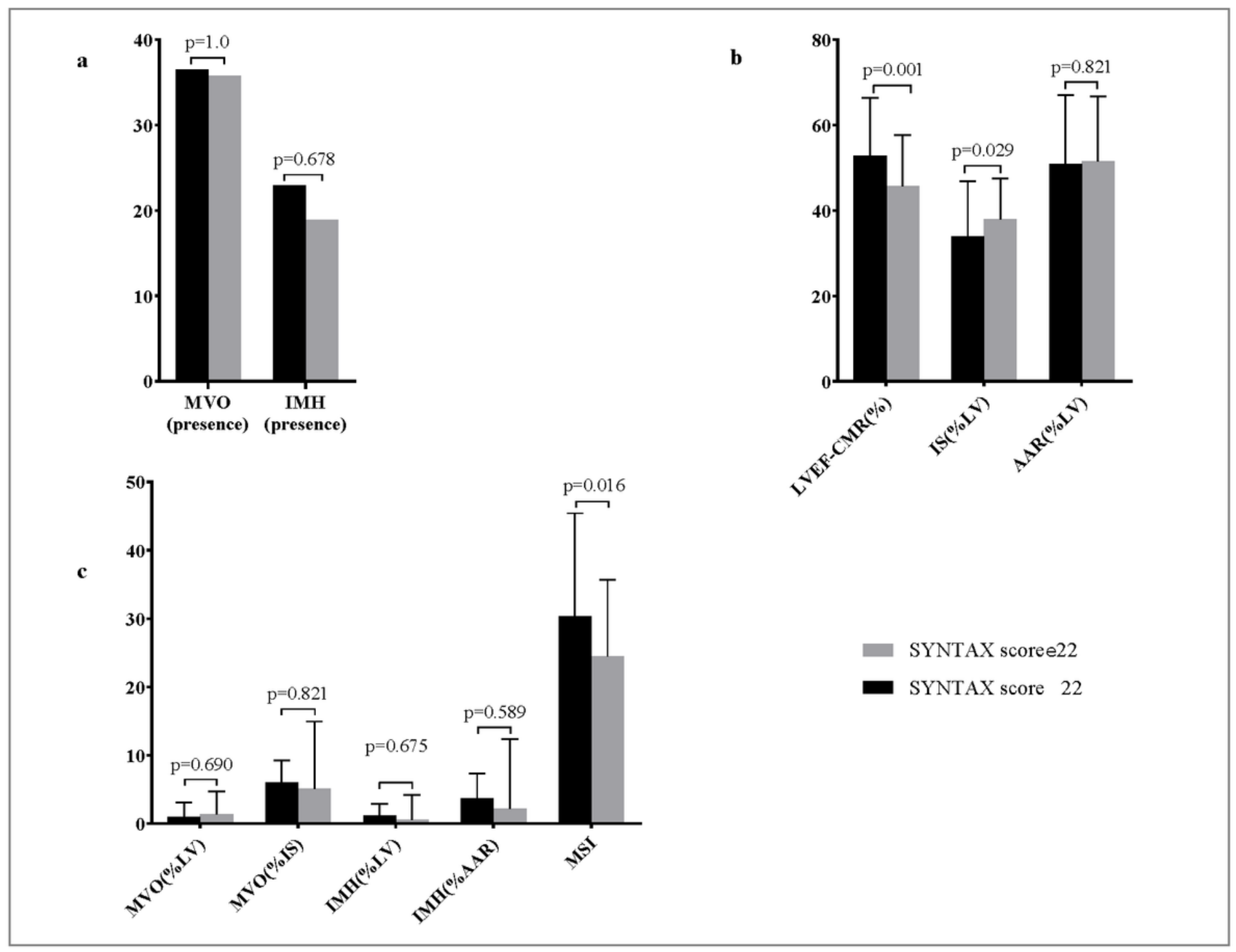

Figure 2

CMR parameters comparation between MHSS group and LSS group MVO microvascular obstruction, IMH intramyocardial hemorrhage, LVEF left ventricular ejection fraction, CMR cardiac magnetic resonance imaging, IS infarct size, LV left ventricular, AAR area at risk, MSI myocardial salvage index

Image not available with this version

Figure 3

Correlations Among SYNTAX score, infarct size (\%LV) and MSI LV left ventricular, MSI myocardial salvage index 


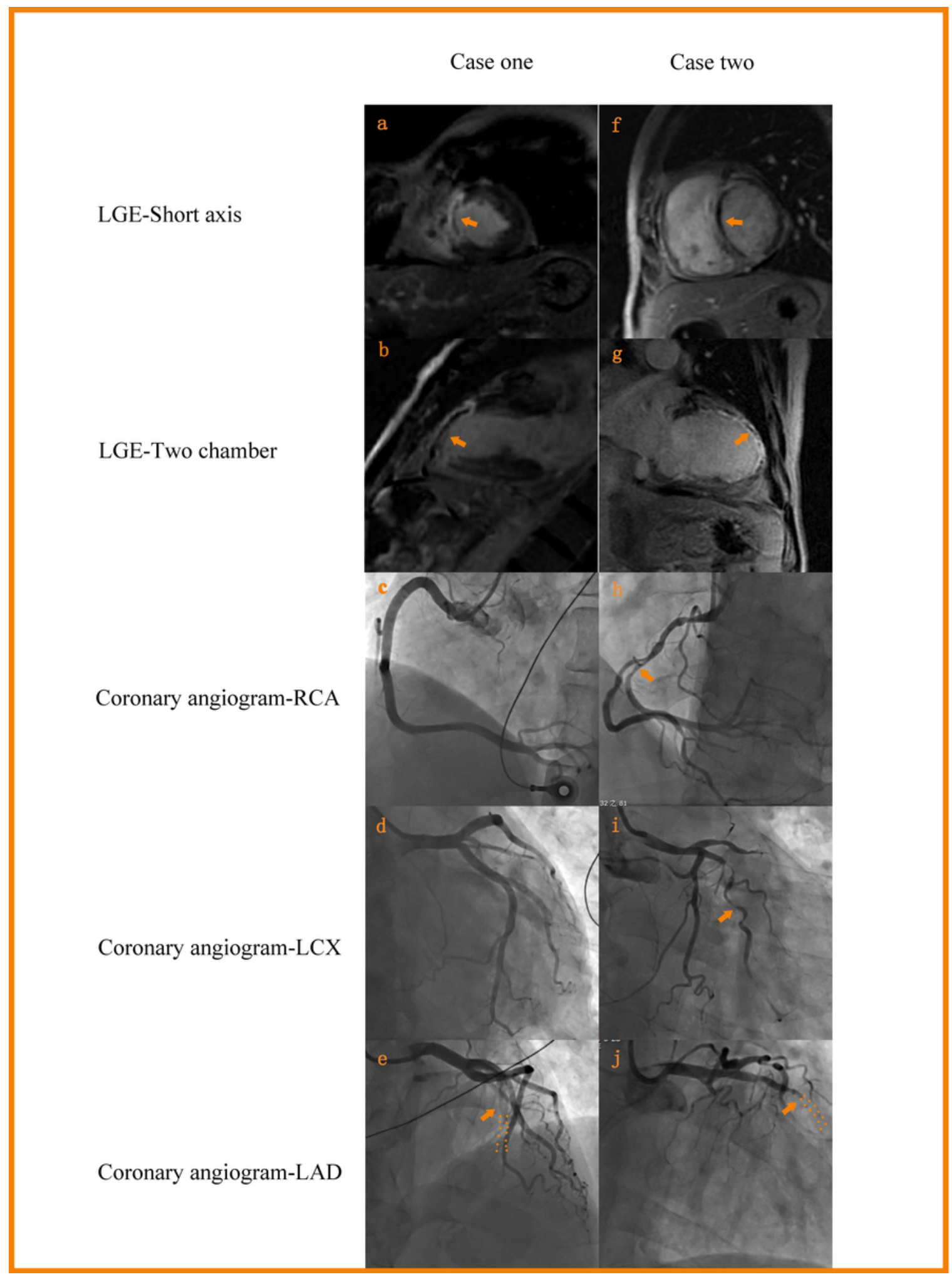

\section{Figure 4}

Two case examples. Case one (a e): A 59 years old man with anterior ST-elevation myocardial infarction was identified to have single total occluded LAD (STNTAX score 18.5 and infarct size 22.74); Case two $(f \sim j)$ : A 64 years old man also with anterior ST-elevation myocardial infarction was identified to have total occluded LAD and diffused diseased intermediate branch and RCA (STNTAX score 32.5 and infarct size 54.91) LAD left anterior descending artery, RCA right coronary artery 

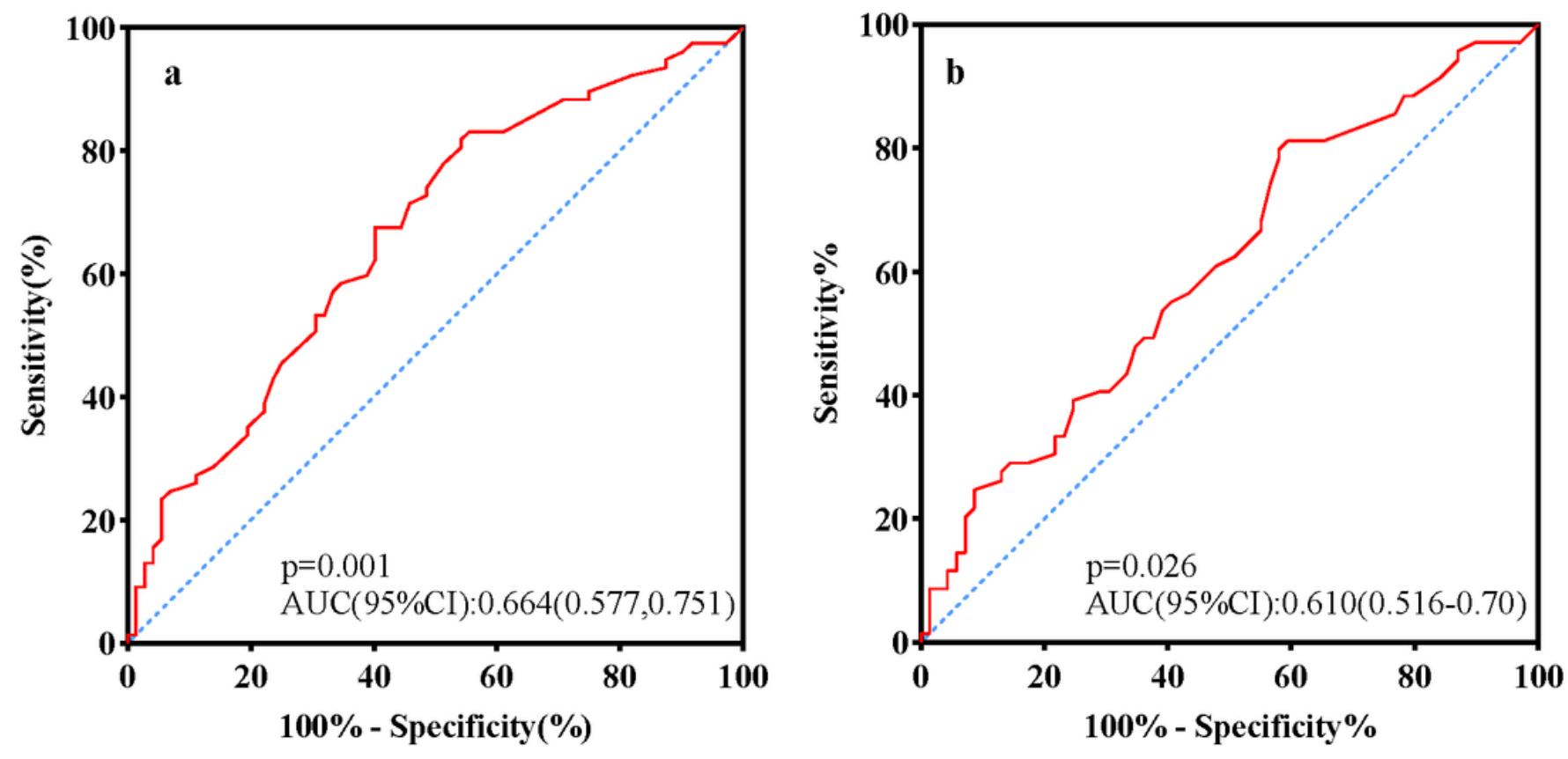

Figure 5

Receiver operating characteristic curves for SS to discriminate IS $\geq$ mean 35.43(a) and myocardial salvage index $\leq$ median28.01(b) 


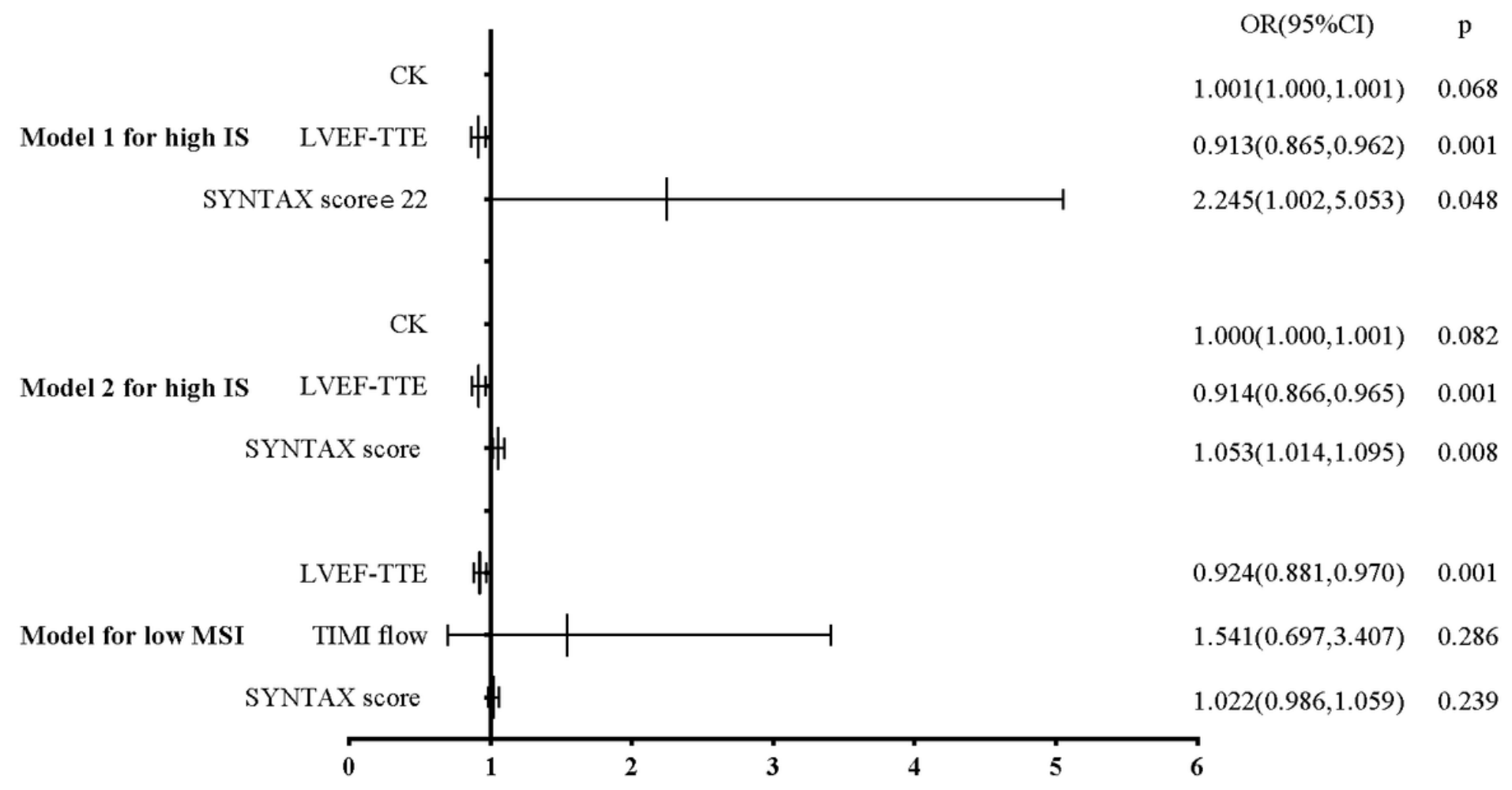

\section{Figure 6}

multivariable logistic regression model for IS $\geq$ mean 35.43 and myocardial salvage index $\leq$ median28.01 OR odd ratio, Cl confidence interval, IS infarct size, LVEF left ventricular ejection fraction, TTE transthoracic echocardiography, MSI myocardial salvage index, TIMI thrombolysis in myocardial infarction 